\title{
A Review of intellectual property rights: The weak link with the African Traditional knowledge
}

\section{JONAI WABWIRE}

wabwirejonai05@kisiiuniversity.ac.ke

\begin{abstract}
Protecting traditional knowledge (TK) has been acknowledged in various discussions under the umbrella of a number of inter-governmental organizations that deal with biodiversity, the environment, indigenous peoples' rights, human rights, among others. It has, however, been difficult to arrive at a consensus on the proper modality that can serve the needs and desires of Indigenous and Local Communities (ILCS) in their economic and cultural participation. The paper examines the requirements for the protection of TK and explores the modalities of TK protection at the international level for regulating the control of, access to and utilization of biodiversity associated with it. It is argued that any modality of TK protection should incorporate defensive and positive protection that address gaps in protecting TK. Protection of TK should, therefore, involve identifying different modalities, including those based on Intellectual Property, to fit the nature and use of TK in particular contexts. The paper makes a case for a shift in strategy for protecting TK by adopting pluralistic modalities that address the protection needs of ILCS, depending on the purpose and the context in which the knowledge is practiced.
\end{abstract}

Keywords: Traditional knowledge, Indigenous and Local Communities (ILCs), pluralistic modalities, intellectual property rights.

\section{INTRODUCTION}

The legal protection of traditional knowledge (TK) systems has become critical issue of global concern. Since the coming to force of the Convention on Biological Diversity (CBD), the international community has broadly recognized the need for protecting TK as a way to reward custodians of biodiversity in the utilization of these resources mainly in biotechnology and other areas. With the increase in the applications of TK and accompanying biodiversity in biotechnology, efforts to provide for effective protection of TK have continued to dominate various discussions and negotiations, without significant success. The discussion in this paper shows a growing realization of the need for the protection of TK in light of the tremendous role TK systems and practices play in the contemporary global economic system. As a specialized branch of the United Nations dealing with intellectual property issues, for example, the World Intellectual Property Organization (WIPO) seeks the protection of TK in "close cooperation with other international agencies and processes" in order to take into account the "full international context of" the protection of TK (WIPO 2007). In accordance with the mandate from the WIPO's General Assembly, Intergovernmental Committee on Intellectual Property and Genetic Resources (IGC) currently conducts "text-based negotiations" to achieve "effective protection" through the conclusion of "international legal instruments on TK (WIPO 2013). Although the negotiations started in 2011, it is apparent from the draft text of the WIPO negotiation, most of which is in square brackets, that further negotiations will continue to narrow the numerous differences among the negotiators. In addition to WIPO, international efforts to protect TK span across a thicket of legal regimes dealing with biodiversity, the environment, indigenous peoples' rights, human rights, among others.

*Address correspondence to: Jonai Wabwire. School of Information Sciences, Department of Communication, Media and Information Sciences, Kisii University. E-mail: Wabwirejonai05@gmail.com, wabwirejonai05@kisiiuniversity.ac.ke

+To cite this article: Jonai Wabwire "A Review of intellectual property rights: The weak link with the African Traditional knowledge". The Journal of Healthcare Ethics \& Administration Vol. 7, no. 4 (Fall 2021): 1-11, https://doi.org/10.22461/jhea.1.71632

This work is brought to you for free and open access by the Institute of Clinical Bioethics (ICB) at Saint Joseph's University, Philadelphia, PA, U.S.A. It has been accepted for inclusion in The Journal of Healthcare Ethics \& Administration by the editorial board and an authorized administrator of the JHEA. For more information, please contact support@jheaonline.org 
In the legal and policy domain of IP across these regimes, the protection of TK has brought several issues, two of which will be the focus of special attention in this paper: first, issues related to the different ways in which the IP system has been used to misappropriate TK. The paper demonstrates this by highlighting the incompatibility between the conventional IP system and the interests of ILCs in respect to TK. Secondly, the article analyses the modalities of TK protection needed, examining the tools that ILCS need to safeguard their interests. Section II clarifies the defining features of TK in respect to the substantive content of possible protection in intellectual property (IP) rights. Section III lays out the imperatives for the protection of TK, highlighting the challenges and difficulties that indigenous and local communities (ILCS) face due to the lack of protection for TK systems and their underlying biodiversity. The discussion in this Section considers conditions that make protecting TK an urgent and necessary measure, assessing the impacts of the existing IP regime. Section IV examines various modalities for protecting TK, such as proposals for defensive community patent system, culture specific protocols of protection, and other methods of protection under existing or amended versions of IP rights as well as those of a public domain approach to protection. Also, the discussion in this Section identifies limitations in dominant approaches for protection in each model. The Section that follows makes a case for a shift in strategy for protecting TK by adopting a pluralistic approach that addresses the protection needs of ILCs depending on the purpose and the context in which the knowledge is practiced. A well-designed protective system for TK at the international level ought to serve the needs of diverse communities who hold TK, the diversity of different categories of TK, and the various ways of using the knowledge. Thus, this article argues that the search for modality of TK protection should transcend a single model and incorporate defensive and positive protection that addresses gaps in protecting TK. Such a search should involve identifying different modalities, including those based on IP, to fit the nature and use of TK in particular global contexts.

\section{THE DEFINITIONAL DIFFICULTY OF TRADITIONAL KNOWLEDGE}

The term "traditional knowledge" According to WIPO (1993) is a shorter form of the phrase "knowledge, innovations, and practices of indigenous and local communities embodying traditional lifestyles" under the "traditional knowledge, innovations and practices". Looking at the definitional scenery of the term, various theoretical dilemmas are encountered due to the complexity of the issues that surround it. In regard to this paper, the definition of TK may involve the description of the distinct elements of the concept from the perspective of: the choice of terminology, identity of the knowledge holders, and the substantive content of what constitutes TK.

\section{A. Choice of Terminology}

Numerous relevant literature and reputable international instruments alternatively apply the following terms to refer to TK: "indigenous knowledge," "local knowledge," "folk knowledge," "community knowledge," "tribal knowledge," "traditional ecological knowledge," and various others (WIPO, 2002). Some of these designations are objectionable for being too narrow. Nonetheless, the distinction between TK and indigenous knowledge stands out as worthy of discussion. According to Silke (2009) the term "indigenous knowledge" is used interchangeably with TK., but there are significant policy and legal implications in the choice of terminology between TK and "indigenous knowledge. Fundamental to the distinction between the terms "traditional knowledge" and "indigenous knowledge," is a distinction between "knowledge held in diverse local and traditional contexts," and "the knowledge systems of peoples identified as having distinct indigenous status," respectively. In respect to the latter, the definition of "indigenous peoples" in international law incorporates standards that exclude certain communities who engage in the creation and maintenance of TK from the category of "indigenous peoples. In reference to ILO (1989) the categories of people that may not fit international law's criteria for indigenousness are sometimes referred to as "local communities. Local communities" may be understood as "farming communities in subsistence farming systems, which do not correspond to the legal descriptions of "indigenous peoples'", or those who "do not wish to use (the indigenous) line of argument to their end." In spite of the different contexts in which the interests of "local communities" and "indigenous peoples" surface in international forums, knowledge held by "local communities" coincides with the knowledge system of "indigenous peoples" in most cases, particularly in the context of agricultural knowledge (Susette Biber-Klemm \& Thomas C., 2006). Therefore, the term "traditional knowledge" includes the knowledge of both indigenous and non-indigenous communities 


\section{THE JOURNAL OF HEALTHCARE ETHICS \& ADMINISTRATION}

Vol. 7 | No. 4 (Fall 2021)

\section{B. Substantive Content}

In efforts for TK protection in international IP forums, the substantive content of TK differs based on distinction between TK as a descriptive broader concept (lato sensu), and TK in a stricter legal and policy sense (stricto sensu). "TK stricto sensu refers to the content or substance of knowledge" integrated to or associated with "the genetic resources that are frequently intertwined with TK." (WIPO, 2000). In this sense, TK refers to "technical" knowhow and the underlying biodiversity to which the knowledge is usually integrated into or is associated with. On the other hand, TK lato sensu refers to "technical know-how, knowledge, and also folklore or traditional expressions and manifestations of cultures in the form of music, stories, paintings, handicrafts, languages..." In regards to WIPO (2000), these include expressions of ideas under the categories of traditional cultural expressions and folklore (TCEs/Folklore), cultural property and cultural resource heritage. In the realm of protection as Irini $(2011)$ posits, legal and policy domain of TCEs and cultural heritages is distinct from that for TK (and its intrinsic components, genetic resources). The discussion in this paper focuses on major questions that arise in efforts for the protection of TK that is related to biodiversity in the narrow sense. Before delving into discussion of the different modalities for TK protection, it is necessary to address the question of why the protection of TK is required. Answering this question provides context for understanding factors that underlie demands to protect TK and provides a basis to assess the effectiveness of a particular modality of TK protection.

\section{THE RATIONALE OF PROTECTING TRADITIONAL KNOWLEDGE (TK)}

The term "Protection" creates confusion as it means very different things in strict intellectual property law and in ordinary usage. "Protection" in intellectual property is usually perceived as a means enforcing private, exclusive economic rights to a specific creation in order to prevent others from using or reproducing it. "Protection" of TK, on the other hand, implies protecting the whole social, ecological, cultural and spiritual context of that knowledge so that it continues to be produced and reproduced. The protection of TK is justified on two grounds. First, because of the value and importance that TK offers to ILCs and to the world population at large. Second, TK protection is required in response to the threats and challenges posed to TK systems from the global IPRs system itself.

\section{A. The Cultural Significance}

TK is important to its holders, ILCS, as an integral part of their cultural heritage. According to Robert, (nd) Many ILCs consider TK as a source of social cohesion, and TK offers a basis for their survival as a community and a pillar of identity to the future generation. The protection of TK is considered part of the implementation of ILCS rights to maintain and to take part in cultural life as recognized in international human rights instruments (Graham D. \& Uma, 2008). The protection of TK would result in concrete realization of the treasured rights of indigenous peoples to preserve their cultural and spiritual identity.

\section{B. The Contribution to Biological Diversity and Ecological Integrity}

Currently, the prominent ground on which to justify the protection of TK relates to its importance in maintaining biological diversity and ecological integrity. Since 1987, a United Nations Committee on the Environment and Development report noted the inability of modern science to provide guidelines for managing natural resources. The report called for the recognition of and greater respect for the wisdom inherent in traditional knowledge systems in this respect (U.N., 1987). For these reasons, international environmental agreements, such as the convention on biological diversity - CBD, expressly recognize the interdependence between TK and biodiversity, and devise strategies to preserve the biodiversity by affording protection to the TK. Thus, the protection of TK closely relates to the protection of the environment and living resources, as the content of TK is mostly entrenched in the biological resources and ecosystems themselves (Erica, 1999). 


\section{THE JOURNAL OF HEALTHCARE ETHICS \& ADMINISTRATION}

Vol. 7 | No. 4 (Fall 2021)

\section{Improving and Preserving Socioeconomic Conditions}

The protection of TK is also justified in the view of significant benefits in broad social and economic terms. First, the protection of TK fulfills the socioeconomic goal of preserving the basic means of survival for a large sector of the world's population in light of the fact that the world's poor satisfy $85 \%$ of their needs for food, fuel, shelter, and medicine from TK-based biodiversity resources. According to Rosemary (2001), approximately 1.4 billion rural people need farm-saved seeds and local agricultural practice for subsistence. In this sense, the protection of TK responds to the sense of perplexity aroused by the "moral gap" in global governance whereby over 1.2 billion people live on less than a dollar a day; $46 \%$ of the world's population live on less than two dollars a day; and $20 \%$ of the world's population enjoy over $80 \%$ of the global wealth.

Beyond fairness and equity, proponents of protection for TK aim to prevent the economic loss to biodiversity-rich countries on the cusp of development. With the increase in the commercial applicability of TK in pharmaceutical and agricultural biotechnology, the lack of protection of TK has prompted the "unregulated and unmonitored taking of biodiversity" through an everexpanding intellectual property regime. First, developing countries lose significant incomes that would likely have been claimed royalties from patents for innovations that utilize TK. Second, as individuals and corporations continue to claim patent rights over TK and its accompanying biodiversity, ILCs may even be unable to use by-products from their own resources unless they pay royalties to others (Velasquez. \& Boulet (1999). This is too unfair. The significance of TK as a means of achieving socioeconomic objectives is not limited to developing countries. Even in industrialized countries, traditional medicine serves as an alternative or complementary medical resource to a large sector of the population. In the US, Australia, Canada or Europe, a large number of the population relies on complementary and alternative traditional medicines. Access to alternative and complementary medicinal resources becomes increasingly limited as pharmaceutical and biotechnology companies continue to claim patents in large areas of biodiversity associated with TK for the medicinal, cosmetic and dietary uses.

\section{Contribution to Scientific Discovery and Biotechnology Development}

Protection of TK is also important to mankind in general because TK systems have contributed significantly to scientific discovery and biotechnology development (William \& Gable (2002). Technological advancement in genetic engineering since the 1980s has allowed researchers to find and to move genetic sequences responsible for particular traits in a plant, or even to move traits from one species to another. Referred to as Rdna by Keith (2009), genetic engineering, this system of genetic manipulation at the molecular level has opened a new era of research and product development in the areas of specialty food and beverage, agriculture, horticulture, personal care, and cosmetics. Screening a huge quantity of molecules to isolate valuable active compounds for agricultural and pharmaceutical use is prohibitively expensive in terms of both time and financial resources because the drastic uncertainty of potential traits requires the screening of all plants. TK served as a critical filter that enhances the effectiveness of the screening process. The motivation to protect TK is not limited to the value and potential importance that it holds. The need to protect TK has also become apparent in light of widespread challenges to TK in the current global IP system. One way in which the need to protect TK is demonstrated is in the context of efforts to prevent third parties' misappropriation and misuse of TK for commercial use through the use of IP.

\section{E. IP Challenges to Traditional Knowledge}

The threats and challenges to TK and their underlying biodiversity arise from the role of IP in transforming the practice of bioprospecting into a more abundant form of biopiracy. Bioprospecting is an age-old and relatively innocuous concept that refers to the legitimate discovery of useful biological resources and the attendant knowledge for commercial applications. This practice is usually conducted with the consent or acknowledgement of TK holders. Bio prospecting contrasts with bio piracy, a term coined as a counterpoise to the allegation of "piracy" of IPRs against developing countries. According to Cynthia (2006) Bio piracy refers to a 


\section{THE JOURNAL OF HEALTHCARE ETHICS \& ADMINISTRATION}

Vol. 7 | No. 4 (Fall 2021)

situation in which biodiversity and its underlying TK are utilized: Without compensation and without the acknowledgment of the intellectual inputs in the development of the useful attributes of the resource.

The bio piracy discourse illustrates inequities in the utilization of genetic resources and their underlying TK through the instrumentality of IPRs in an era that measures economic activities by the extent of production, distribution, and use of knowledge and ideas. As instruments to control information and ideas, IPRs in general, and patents in particular are used to allocate rights from the utilization of biodiversity as a basis for "inventions and creativity" in a biotechnological process.

The agreement on trade-related aspects of intellectual property rights (TRIPS) brought changes in the jurisprudence of IPRs. These changes play a critical role in perpetrating bio piracy. The conventional standard for the protection of patents is that the subject matter of patentable invention must be "new, must involve an inventive step, and should be capable of industrial application." The conventional justification for such protection is utilitarian, that limited monopoly to those who come up with inventions induces innovation and intellectual productivity; if the law does not protect IPRs, there will not be enough incentive to innovate, and thus, society will be without the benefits of innovation.

The TRIPS Agreement incorporates the above conventional standards for the protection of patents, along with other standards in the field of trademarks, copyrights, industrial designs, and geographical indications. In addition, the TRIPS Agreement obliges countries to recognize patents on microbiological life forms. As a result, patent offices in the industrialized world, notably the United States Patent and Trademark Office (USPTO), easily determine the criteria of "novelty and inventive step" in a manner that enables biotechnology companies in the pharmaceutical and agricultural industries to establish patent rights on different life forms (Cynthia 2006). This opened the way for patent claims by multinational companies, such as Monsanto, to monopolize the market for "new" plant and animal varieties derived from existing genetic resources and TK through biotechnological processes.

A number of genetically modified (GM) crop varieties are currently subjects of so called gene patents - patents accomplished through acts of isolating and purifying genes outside an animal, plant, or microorganism. In principle, these acts simply uncover something that already exists, and as such, the rationale for "gene patents" runs against the conventional justification of patents - that protection is needed to reward individuals who come up with innovations and creations that do not previously exist. In the post-TRIPS regime of IP, a more likely effect of IPRs has become their incentive for commercialization of inventions that already exist, instead of promoting inventions and creativity. The effect of IPRs in promoting the commercialization of inventions and in maximizing the profitability of inventions is "distinguishable from, and should not be conflated with, the promotion of inventiveness and creativity" as presumed by the utilitarian logic (Chidi, 2009)

\section{THE MODALITIES OF PROTECTING TK}

In reference to the problems outlined above, there have been significant efforts to provide for the protection of TK in international IP law and policy. Since the TRIPS Agreement constitutes an overarching global IP Instrument, first efforts for the protection of TK arose within the TRIPS Council of the WTO. However, forms of IPRs under the TRIPS Agreement are inadequate to protect TK and TKrelated resources for a number of reasons.

First, most forms of IPRs emphasize, to a large extent, individual intellectual achievements. As a result, the legal identity of right-holders is inherently individualistic or corporeal. For ILCS, however, "innovations are cultural properties" in the sense that to a large degree, "they are the product and property of a group." According to Xavier (2008) TK is more of "a means of developing and maintaining group identity and survival," than of promoting individual gain. Tonina (2004) posits that the modern IPRs do not, in most cases, take account of the collective nature of TK.

Secondly, the subject matter of protection in some IPRs, such as in patents, is required to be "new." TK is rather knowledge built up over time in an incremental fashion. Chidi (2004) posits that the focus of the extant IPRs on "new knowledge" through the criteria of novelty and originality puts TK out of the realm of protection because TK is built on knowledge accumulated over generations and continues to evolve in response to changing and emerging needs. 


\section{THE JOURNAL OF HEALTHCARE ETHICS \& ADMINISTRATION}

Vol. 7 | No. 4 (Fall 2021)

Thirdly, most forms of IP accord their owners a limited term of protection. TK frequently shows continuity, and is marked by its evolution over time and its cross-generational nature. ILCs emphasize that their TK is a heritage that must be protected in perpetuity, for the lifetime of the culture, not merely for some fixed period (Erica 1999)

In circumstances where TK may qualify for protection under IP regimes, certain challenges arise for the communities that want to benefit from the system. IPRs tend to favour corporeal and other non-indigenous interests, as they are mostly subject to economic power and manipulation. The procedures for registering the rights are, in general, expensive, complicated, and timeconsuming for most TK-holders (Vandana 2001)

Due to difficulty of achieving TK under the IP regimes in the TRIPS paradigm of the WTO, however, efforts were shifted to other international forums that are entrusted with normative concerns beyond IPRs, such as those based on environment, biodiversity, human rights, health and development. Key regimes of international law that seek to protect TK in areas that directly relate to IP law and policy include the WIPO, the CBD, and the Food and Agricultural Organization FAO (1989). The breadth of discussion across the different international regimes marks broad recognition of the relevance of TK in the diverse areas of IP law and policy. Yet, the extent, nature, and effectiveness of TK protection depend on the instruments chosen as a model for protection. Despite general understanding of the need to provide protection for TK, significant gaps can be found in the range of measures and options discussed and proposed, as is manifest in the WIPO negotiation process for protecting TK. The legal mechanisms to protect TK that are widely accepted in the various forums can generally be grouped into three major categories: an Access and Benefit Sharing model; Sui Generis model; an IP-based model.

\section{A. The Access and Benefit Sharing System}

The Access and Benefit Sharing (ABS) system is a system under the CBD framework to regulate the conditions for access to and use of genetic resources and the sharing of benefits from their utilization with ILCs. By creating a regulated arrangement between users and providers of biodiversity, the ABS system aims to contribute to the conservation of biological diversity and the sustainable use of its components through the fair and equitable sharing of the benefits arising from the utilization of genetic resources and associated TK.

The bass for $A B S$ arrangements are laid down under the CBD. The major ones include recognition of the sovereign rights of States over their natural resources, requirement for users of genetic resources to obtain PIC, conclusion of mutually agreed terms between users and providers, and finally, grant of access to genetic resources for environmentally sound uses. ABS remained an integral part of the ABS system only as voluntary mechanism Bonn (2002). Despite significant progress in the development of the principles that the CBD introduced, including the conclusion of the Nagoya Protocol and the Bonn Guidelines, there has not been progress on making $A B S$ requirements as mandatory obligations in applications for IP protection.

The requirement of $A B S$ arrangement as a basis for voluntary contractual arrangements, rather than as part of requirements in applications for patents, leaves the existing IPRs system intact. At best, the successful conclusion of ABS arrangement makes the existing IPRs regime more transparent, fair, and equitable. In this case, the system of ABS falls short of satisfying demands to accommodate TK through reform of the IPRs system. It is, therefore, questionable as to whether the object of $A B S$ is exploitation of biodiversity resources or their conservation.

The model of ABS is based on the reasoning that TK holders will be incentivized to preserve and conserve biodiversity resources through contractual sharing of benefits, which would be derived from private individuals' patent rights over "inven tions" that utilize genetic resources and associated TK. In effect, the current ABS arrangement is built on and "adopts classical economic assumptions regarding the nature of conservation, and the preferability of private property regimes to systems of common property." The CBD's focus on economic benefits through individuals' establishment of IP rights on genetic resources and TK may increase TK's commercialization and inevitably, its high utilization. $88 \mathrm{In}$ effect, this runs contrary. 


\section{THE JOURNAL OF HEALTHCARE ETHICS \& ADMINISTRATION}

Vol. 7 | No. 4 (Fall 2021)

\section{B. Sui Generis Modalities of Traditional Knowledge Protection}

The sui generis option to protect TK incorporates numerous proposals that have variations, each with their own complex conceptual and practical implications. Overall, the sui generis models of protection propose the recognition of tools ingrained in the customary roots of TK. In reference to WIPO (2009), there are two major varieties of TK protection under the sui generis model that are briefly explored below.

\section{Defensive Community Patent System}

One of the prominent proposals among the sui generis variation is referred to as the "defensive community patent" system. Given the historical flexibility in the criteria for patentability in IP law, this proposal recognizes that the system of IP may "creatively" be modified to provide protection to TK. The "defensive community patent" model favours the recognition of a strong system of IP that is suited to the salient features of TK in the use of biological resources for biotechnological applications. As owners of IP rights, ILCS would be in a position to prevent third parties' establishment of IP rights over their resources. The legal effect of the use of TK without ILCs' consent would, in this case, be considered an infringement of legally recognized property rights in the IP regime.

As effective and efficient the community patent model sounds, it can be challenging to incorporate it into existing regimes of IP law. Given the limited role of ILCs in international law-making, it is unlikely for industrialized country negotiators to allow a compromise that accommodates TK in a manner suggested under this approach. The stakes are high for industrialized countries for which IPRs-based products constitute the largest share of exports. According to Layton, and Wiseman, (2008), to recognize robust property rights in the form of communal patent protection for TK, it can be difficult to strike a balance between the rights of ILCs under a communal patent system and the needs of multinational companies who are desperate to find replacements for their patents on profitable drugs and agro-technology products that are set to expire after two decades of the TRIPS Agreement's enforcement. Even if successful, the defensive nature of the proposed protection may not appeal to the interest of ILCs who may want to capture and control the economic value of their knowledge to fairly participate in the global economy and to satisfy their socioeconomic needs.

\section{Culture Specific Protocols of Protection}

Another sui generis option looks to culture specific protocols that need to be developed from the customary roots of TK (Kathy 2006). This option, as Kathy explains, proposes protective modalities for TK through "an investigation of the practical uses of private law at the community level for the protection of custom." Fuelled by "disappointing" efforts to protect TK that often yield "compromised and limited" results in international and national law-making efforts to protect TK, this approach calls for the consideration of protective tools that are based on modalities and elements compatible with TK's inherent characteristics and history. This variation of sui generis modality is essentially premised on the notion that an adequate protection of TK cannot be guaranteed even by incorporating new elements of IPRs because "structurally many traditional societies do not respond to the western system, but have their own methods of economic, political, social, and cultural articulation." (Kathy 2006)

In its submission to WIPO, for example, the Indigenous Peoples Council on Bio colonialism (IPCB) notes that: True protection for indigenous knowledge cannot be based on IPRs in their existing or adapted form (i.e., community copyright or community marks) (WIPO/GRTKF (2006). New sui generis protections should be based on Indigenous peoples' customary laws, which are the true sui generis protections. The IPCB distinguishes between "the development of sui generis for internal use and for external use," and prefers the former over the latter. WIPO also acknowledges the existence of similar sui generis protective tools among ILCS, although most of WIPO's activities in the sui generis option generally concentrate on adaptations of extant IPRs to regulate the external use of TK.

Evidently, the sui generis option of protecting TK through its customary roots represents the most effective approach to provide protection that is comprehensive, yet tailored to the specific context of TK. The prospect for the recognition of this option at the international level seems remote given that TK does not, as yet, seem to be sufficiently integrated with the modern legal 


\section{THE JOURNAL OF HEALTHCARE ETHICS \& ADMINISTRATION}

Vol. 7 | No. 4 (Fall 2021)

infrastructure. The concerns raised in the assessment of the sui generis defensive communal patent system may, mutatis mutandis, apply to this option.

\section{Protection under Existing Versions of Intellectual Property Rights}

Given the effectiveness of IPRs in regulating economic relations, segments of stakeholders have recently become receptive to the possible use of IP as frameworks to protect TK for external use (WIPO 2002). Suggestions to protect TK through IP mostly include either the use of existing IPRs, or the use of their modified versions in some cases, or the use of their amended version in others. Examples in the latter category include the application of case law interpreting unmodified statutes of IPRs in a manner that responds to the interest of ILCs. In this line, the Australian Aboriginal artists successfully invoked claims of copyrights and unfair trade practices against carpets imported from Vietnam that replicated Aboriginal arts (Michael 1994). In resolving the dispute that arose, the Federal Court of Australia granted compensatory damages for "personal suffering" to take account of cultural aspects. It decided that even though only individuals could be recognized as copyright owners: There may be scope for the distribution of the proceeds of the action to those traditional owners who have legitimate entitlements, according to Aboriginal law, to share the compensation paid by someone who has, without permission, reproduced the artwork of an Aboriginal artist."

The jurisprudence developed from this and similar cases have generally helped to introduce the issue of TK into the Australian IPRs establishment. For example, the National Indigenous Arts Advocacy Association in Australia adopted the Indigenous Label of Authenticity in 1999 to help promote the marketing of the art and cultural products, and to deter the sale of products that are falsely labeled as originating from Aboriginal peoples. The result of the certification of authenticity in this manner, however, has not proved fruitful and thus, the initiative has been abandoned (Peter, 2004).

In New Zealand, existing IPRs are used to provide defensive measures of TK protection (WIPO 2002). The New Zealand Trade Marks Act was amended to prohibit the registration of trademarks that would likely offend a significant segment of the community, including the indigenous Maori people. In addition, the Act allows the invalidation of a registered mark upon application by a person "culturally aggrieved," even if the mark is distinctive of a registered owner. Bearing in mind the holistic nature of TK, it combines the use of IPRs with initiatives for sui generis approach to TK.

In Canada, according to WIPO (2002) there has yet to be any amendments to IPRs legislation based on protection for TK and TKbased resources. As a working paper from the Department of Indian and Northern Development indicates, however, indigenous peoples in Canada directly utilize existing Copyrights and Trademark systems to establish rights on the products of their knowledge (Daniel 2003). This includes the use of copyrights in the woodcarvings of Pacific coast artists, including masks and totem poles, and in the silver jewelry of Haida artists.

\section{The Public Domain Approach to Protection}

Historically, the idea of the public domain is construed in different ways. In the post-TRIPS Agreement movement for the protection of TK, two positions can be identified in regarding the protection of TK from the perspective of the public domain. In the first, the idea of public domain is invoked as a defensive strategy against the encroachment of property rights to biodiversity and the underlying TK. In this respect, the public domain approach converges with what is called the "access to knowledge" movement and is often raised as a tool to curb the expansive reach of IPRs over "inventions" that utilize TK. In this sense, protecting the public domain from misappropriation by IPRs through different legal strategies is equated to protecting TK. Secondly, opponents of the protection of TK also embrace the public domain approach to support their claim that TK falls outside the scope of any form of protection. Some adherents of the public domain approach consider TK and TK-related resources as "raw materials" for invention and, thus, only subjects of real property rights for which owners of TK could not claim any kind of IP-based protection. Even though benefits may be derived through ABS systems, a public domain approach to protecting TK rewards ILCs only as wardens of biodiversity not also as cultivators and owners 
The relegation of TK to the public domain denies the intellectual worth and value of TK, and conflates TK with the so-called products of nature. Treating TK as part of the public domain and presenting it in binary contrast to IP amounts to invalidating TK as "ancient, static, and natural, rather than modern, dynamic, scientific and cultural invention."In this sense, the idea of public domain considers TK just as a "raw material" for innovation and sharing of benefits with communities who might not have approved the utilization of the knowledge or biodiversity in the first (Vandana 2001).

\section{TOWARDS A PLURALIST APPROACH IN PROTECTING TK}

One of the major problems with the number of approaches and legal tools for protecting TK under consideration in different international law forums is that most of the modalities target the protection of TK in its "holistic" context. This is based on the presumption that TK cannot be separated from the cohesive whole and cannot be compartmentalized to fit to existing Western systems of IP, as scientific knowledge can. While the holistic context of TK holds true for TK, in general, the protection of TK may be achieved through diverse mechanisms that should be fashioned or refashioned to provide protection that is complementary and mutually supportive to a chosen modality of protection. In the face of the diverse modalities for the protection of TK, this article proposes a pluralist approach in which diverse mechanisms may be employed to fit to the diverse ways of applying TK.

The frontiers of "creativity" in the field of TK are expressed through wide areas of practice, such as economic, agricultural, medicinal, spiritual, and cultural due to the various ways of using the knowledge by diverse group of ILCs. As important and pertinent as some of the approaches and modalities - particularly the sui generis options - are to the protection of TK, choosing a particular modality of TK protection over another may obscure differences in the needs and interests of ILCs. It might not be feasible or even desirable to find one form of protective regime that covers all aspects of TK, given the role of TK in diverse areas of socioeconomic, cultural, ecological and even technological domains. As such, the holistic feature of TK might be better accommodated through protection based on different legal mechanisms that are suited to the different facets of TK for internal use (among the communities) and for external use - outside of the communities (WIPO 2009).

TK for internal use refers to aspects of TK that have significant spiritual and cultural value more than economic ones. For these categories of TK practices, defensive approaches, and more pertinently, culture-specific protocols of sui generis systems may be important and effective tools. Without necessarily excluding any form of sui generis modalities that may be suited to a holistic context of TK protection, however, other methods for positively protecting TK should be considered since a mere defensive system of protecting TK is insufficient to satisfy the needs and expectations of ILCs in the diverse contexts of TK (WIPO 2009).

This necessity arises for categories of TK that are commercially available, for which, IP-based protection would enable ILCS to acquire economic advantages by fairly participating in the global economy. For the above reasons, irrespective of the appropriate model of protection for TK in general, efforts should be made to explore whether IP instruments such as geographical indications can serve a purpose as models of IP-based protection for TK-related resources. A large number of TK related agricultural resources have significance to ILCS as a means of supporting their livelihood through economic exchanges. This is the case for a significant variety of agricultural products that are produced through the exercise of traditional skills and techniques such as, for example, in the case of Canadian wild rice (Manoomin), Ethiopian Coffee, Basmati Rice, Ghanaian Cocoa, South African Rooibos tea, Kenyan Kericho tea, etc. Consumer appetite for these products is high in international markets. In this context, the proper question is not just whether IP rules allow the misappropriation of and bio piracy of TK, but also, whether IP can be used to empower ILCs to use their knowledge and resources to share fairly in the riches and abundances of the global economy by participating in international trade(WIPO 2000). In relevant circumstances, IP rules should and can be fashioned or refashioned to suit the needs and expectation of ILCs to participate in transactions over their resources in international trade, not to just defensively protect these resources from misappropriation. 


\section{THE JOURNAL OF HEALTHCARE ETHICS \& ADMINISTRATION}

Vol. 7 | No. 4 (Fall 2021)

\section{CONCLUSION}

Different priorities dictate the contents of modalities for protecting TK reviewed thus far. Earlier approaches mainly focused on fending off the reach of IP based on modalities for protecting the public domain which genetic resources and associated TK have been considered to be a part of. The limitations in the modalities as well as the conditions in TK protection discussed thus far necessitate a shift in strategy towards more focused approach that takes into account pertinent realities. The discussion in this article shows a shift from this focus to allow a degree of IP-based enclosure that is necessitated by a desire to enhance the competitiveness and overall empowerment of ILCs in their participation in the global economy. In the diverse contexts of TK, IPbased mechanisms may be used to afford protection to TK holders for their commercially available products.

Thus, the search for an appropriate modality of TK protection should transcend a single model. Some categories of TK can be inherently inappropriate subjects of protection under market-oriented IP tools. The development of sui generis defensive regime built upon the inward looking cultural protocols that already exist among the community would, in this case, respond to the needs of ILCs. In circumstances where a particular TK-related agricultural resource is commercially significant, ILCs should have the opportunity to access market-based forms of protection, including those based on IP, to fit the nature and use of TK in particular situations. In this context, formulation of an internationally acceptable regime that incorporates different legal means of TK protection is necessary. Efforts for TK protection at the international level should, therefore, be geared towards identifying different regimes based on the nature and use of the knowledge in the respective category. In this sense, IP-based protection through such tools as geographical indications (GIs) may be used to accommodate aspects of TK-based "creativity" in agricultural production.

\section{REFERENCES}

Bonn (2002) Guidelines on Access to Genetic Resource and Fair and Equitable Sharing of the Benefits Arising out of their Utilization, COP6,

Chidi O (2009), Beyond Theories: Intellectual Property Dynamics in the Global Knowledge Economy, 9 WAKE FOREST INTELL. PROP L. J. 104, 121.

Cynthia M. (2006) Biopiracy and Beyond: A Consideration of Socio-Cultural Conflicts with Global Patent Policies, 39 U. Mich. J.L. Reform 433, 450.

Daniel J. G, (2003) Spiritual but not Intellectual? The Protection of Sacred Intangible Traditional Knowledge, 11 CARDOZO J. INT'L \& COMP. L 468, 491-494 (2003)

Erica D. (1999), Protection of the Heritage of Indigenous Peoples cited in David R. Downes \& Sarah A. Laird, Innovative Mechanisms for Sharing Benefits of Biodiversity and Related Knowledge: Case Studies on Geographical Indications and Trademarks.

FAO (1989) Agreed Interpretation of the International Undertaking, F.A.O. Res. 4/89, Annex I, 25th Sess., at Art. 7 (Nov. 11 $29,1989)$ (describing the rights registration procedure).

Graham D. \& Uma s., (2008), Global Intellectual Property Law: Commentary and Materials.

ILO (1989) International Labour Organization, Convention No.169 Concerning Indigenous and Tribal Peoples in Independent Countries, June 7, 1989,,28 I.L.M.1382. The ILO Convention,

Irini A. (2011). Stamatoudi, Cultural Property Law and Restitution: A commentary to International Conventions and European Union Law.

Kathy B. (2006) Alternative Intellectual Property? Indigenous Protocols, Copyleft and New Juridifications of Customary Practices, 6 MACQUARIE L. J. 65, 83..

Keith A (2009), Farm Seeds of Dispute: Intellectual Property Rights and Agricultural Biodiversity, 3 GOLDEN GATE U. ENVTL. L.J.79, 137.

Layton, R. and Wiseman, M. (2008), Distinctive Values in African Exports: How Intellectual Property Can Raise Export Income and Alleviate Poverty, Light Years IP, Philadelphia.

Milpurrurru and Others v Indofurn Pty Ltd and Others

Peter D. (2004) Towards an International Framework for the Protection of Traditional Group Knowledge and Practice, UNCTAD 32-33.

Robert G. H., (nd) , The Interconnection of Intellectual Property and Cultural Property, First People's Cultural Council 1, 2, www.fphlcc.ca/downloads/interconnection-of-ip-cultural-property.pdf.

Rosemary J. C,, (2001) The Recognition of Indigenous Peoples' and Community TK in International Law 14 St. Thomas L Rev. 


\section{THE JOURNAL OF HEALTHCARE ETHICS \& ADMINISTRATION}

Vol. 7 | No. 4 (Fall 2021)

Silke von lewinski (2009) Indigenous Heritage and Intellectual property: Genetic resources, traditional knowledge and folklore, (hereinafter von Lewinski).

Susette Biber-Klemm \& Thomas C., (2006). Rights to plant genetic resources and traditional knowledge: Basic issues and perspectives 19.

Tonina S (2004) , Indigenous TK and Intellectual Property Rights, Parliamentary Research Branch Political and Social Affairs Division 1, 5. http://www.parl.gc.ca/content/lop/researchpublications/prb0338-e.pdf .

U.N. (1987), Development and International Cooperation: Environment: Rep. of the Secretary-General, Annex 971,74, U.N. DOC. A/42/427.

Vandana S, (2001) Protect or Plunder?: Understanding Intellectual Property Rights, London: Zed Books, .

Vandana S. (2001), Protect or plunder?: understanding intellectual property rights, 65 (London: Zed Books, 2001).

Velasquez G. \& Boulet P, (1999) Essential Drugs in the New International Economic Environment, Bulletin of the World Health Organisation.

William D. Coleman \& Melissa Gable (2002), Agricultural Biotechnology and Regime Formation: A Constructivist Assessment of the Prospects, 46 INT'L STUDIES QUARTERLY 489,

WIPO (1993) Report on Fact-finding Missions on Intellectual Property and Traditional Knowledge, WIPO Publication No. 768, 2001; U.N. Convention on Biological Diversity, opened for signature June 5, 1992, 1760 U.N.T.S. 30619, Art. $8(j) .(e n t e r e d$ into force on Dec. 29, 1993) [hereinafter, “CBD"].

WIPO (200), Intergovernmental Committee on Intellectual Property and Genetic Resources, Traditional Knowledge and Folklore, Consolidated Survey of Intellectual Property Protection of Traditional Knowledge, 20 n.44 (July 7-15, 2003) available at http://www.wipo.int/edocs/mdocs/tk/en/wipo_grtkf_ic_5/wipo_grtkf_ic_5_7.doc).

WIPO (2002) Intergovernmental Committee on Intellectual Property and Genetic Resources, Traditional Knowledge and Folklore, Review of Existing Intellectual Property Protection of Traditional Knowledge.

WIPO (2002), Intergovernmental Committee on Intellectual Property and Genetic Resources, Traditional Knowledge and Folklore, TK - Operational Terms and Definitions, Annex I, 3rd Sess. (June 13-21, 2002) (providing a non-exhaustive list of 20 terminologies used to refer to TK); 12 Fordham Intell. Prop. Media \& Ent. L.J. 753, 782 (2002).

WIPO (2007) Intergovernmental Committee on Intellectual Property and Genetic Resources, Traditional Knowledge and Folklore, Genetic Resources: List of Options, 1, 13, 11th Sess.,(July 3-127) available at http://www.wipo.int/edocs/mdocs/tk/en/wipo_grtkf_ic_11/wipo_grtkf_ic_11_8_a.pdf

WIPO (2009) Traditional Knowledge: Key to a Diverse and Sustainable Future, Intellectual Property and Traditional Knowledge, WIPO Publication No. 920.

WIPO, Intergovernmental Committee on Intellectual Property and Genetic Resources, Traditional Knowledge and Folklore, Traditional Knowledge and Folklore Agenda Item 35, 1, 1 43rd Sess. (Sept. 23-Oct. 2, 2013) available at www.wipo.int/export/sites/www/tk/en/igc/pdf/igc_mandate_1415.pdf.

WIPO/GRTKF (2006) Traditional Knowledge. WIPO/GRTKF/IC/10/5 (Revised Draft Objectives and Principles on the Protection of Traditional Knowledge). Geneva.

Xavier S (2008). , Human Rights and Intellectual Property Rights, in Carlos M. Correa and Abdulqawi A. Yusuf, Intellectual Property and International Trade: The Trips Agreement 394 